\title{
Semantic Epistemology: A Brief Response to Devitt
}

\author{
Edouard MACHERY
}

Received: 26.3.2012

Final version: 26.3.2012

BIBLID [0495-4548 (2012) 27: 74; pp. 223-227]

ABSTRACT: In this article, I argue that philosophers' intuitions about reference are not more reliable than lay people's and that intuitions about the reference of proper names and uses of proper names provide equally good evidence for theories of reference.

Keywords: semantic epistemology; semantic intuitions; expertise; reference.

RESUMEN: En este artículo defiendo que las intuiciones de los filósofos sobre la referencia no son más fiables que las de los legos y que las intuciones sobre la referencia de los nombres propios y los usos de los nombres propios ofrecen evidencia de igual valor para las teorías de la referencia.

Palabras clave: epistemología semántica; intuiciones semánticas; expertos; referencia.

\section{Introduction}

Michael Devitt's (2012) thoughtful article "Whither experimental semantics?" responds to three articles I have authored or coauthored (Machery 2012; Machery and Stich 2012; Machery et al. forthcoming), and makes two novel contributions to the evolving debate about the epistemology of semantics': A plea for the Expertise Defense and a sketch of what Devitt takes to be the proper method for confirming theories of reference. Focusing exclusively on these two novel contributions, I argue that philosophers' intuitions about reference are not more reliable than lay people's - if anything, they are probably worse - and that intuitions about the reference of proper names and uses of proper names provide equally good evidence for theories of reference. ${ }^{2}$ In Section 2, I argue that it is unclear whether experts' intuitions about reference are more reliable than, and thus preferable to, lay people's. In fact, as I show in Section 3, they may even be less reliable and thus less preferable. Finally, I turn to the contribution of corpus and production studies to the confirmation of semantic theories.

${ }^{1}$ I propose to call this area of inquiry "semantic epistemology" by analogy to "moral epistemology": While the latter is concerned with the justification of moral judgments and moral theories, the former is concerned with the justification of semantic judgments and semantic theories.

${ }^{2}$ I will be assuming throughout that there is such a thing as reference (although, as Devitt notes, I have expressed doubts about this in Machery and Stich 2012), and that we can have better or worse theories about reference. 


\section{Should Experts' Intuitions about Reference be Preferred?}

\subsection{Two Unanswered Concerns}

The Expertise Defense is, roughly, the view that experimental findings about lay people's intuitions do not bear much (if at all) on philosophical controversies because lay people's intuitions are less reliable than philosophers' (Machery 2011). Devitt has endorsed the Expertise Defense about semantic intuitions in his (2011) critique of Machery et al. (2004) and Mallon et al. (2009), and he has responded to some of my objections to this line of argument in his "Whither experimental semantics?". Unfortunately, Devitt's response fails to address some of the concerns I raised.

On Devitt's view, philosophers are likely to have better intuitions about reference than lay people because they have better theories. Unfortunately, Devitt does not explain in any detail how philosophers' theories of reference enhance the reliability of their intuitions. This silence is a striking shortcoming considering that Devitt has repeatedly criticized proponents of the Voice of Competence for failing to explain how linguistic competence could be the source of people's metalinguistic intuitions (e.g., Devitt 2012, 15-8).

Devitt cannot ignore this request for explanation since it is dubious that philosophers' theorizing about reference can really enhance the reliability of their intuitions about reference. First, the theories of reference developed by philosophers of language disagree about almost everything, and one wonders what feature these theories have in common that could render the intuitions of philosophers of language more reliable than lay people's. Similar concerns were expressed in Section 3.1 of Machery 2012, but Devitt did not address them.

Second, even when scientists have better theories than lay people, their intuitions are not always improved by these theories, and it is unclear why Devitt thinks that intuitions about reference would be any different. For instance, statisticians' and psychologists' statistical theories do not influence, and thus do not improve, many of their statistical intuitions (even those about simple statistical issues such as the significance of sample size). Kahneman writes $(2011,5)$ :

In spite of years of teaching and using statistics, we [Kahneman and Tversky] had not developed an intuitive sense of the reliability of statistical results observed in small samples. Our subjective judgments were biased: we were far too willing to believe research findings based on inadequate evidence and prone to collect too few observations in our own research.

Thus, even if one grants that philosophers of language have better theories of reference than lay people, it does not follow that philosophers' intuitions about reference are more reliable than lay people's. Similar concerns were expressed in Section 3.2 of Machery 2012, but Devitt did not address them.

Perhaps Devitt did not address these concerns because he believes that philosophers' theories could fail to improve their intuitions only if the Voice of Competence were true, but this would be a mistake: Even if the Voice of Competence is false, philosophers' explicit theories need not influence their intuitions (Machery 2012, Section 3.2). 
Some findings mentioned by Devitt in "Whither experimental semantics?" suggest in fact that, just like statistical intuitions, many linguistic intuitions are probably not influenced by linguists' theories. While syntacticians and semanticists have undoubtedly better theories than lay people about many linguistic properties, their intuitions are often identical to lay people's (Devitt 2012, 22). Consistent with Devitt's views, this may be the case because the intuition-eliciting stimuli are so simple that even a minimum amount of expertise (the amount lay people possess) is sufficient to get them right (Devitt 2012, 23). ${ }^{3}$ Alternatively, lay people and linguists may have the same intuitions because often linguists' theories do not influence their intuitions. This second explanation is better since, contrary to what Devitt would predict, linguists and lay people often have the same intuitions even for difficult stimuli.

\subsection{Empirical Evidence about Experts' Intuitions}

In "Expertise and intuitions about reference," I reported some new empirical results: While philosophers of language and semanticists are more likely than lay people to have Kripkean intuitions about the reference of proper names in a Gödel-style case, sociolinguists, historical and anthropological linguists, and discourse analysts are less likely to have Kripkean intuitions than lay people. I tentatively took these findings to undermine the Expertise Defense because expertise cannot improve reliability if it makes some groups of experts more Kripkean and others more descriptivist. Devitt dismisses this conclusion on the grounds that sociolinguists, historical and anthropological linguists, and discourse analysts have no expertise about reference $(2012,24)$.

However, this response is inappropriate for the reasons already discussed in Machery (2012, 51-2): Sociolinguists as well as historical and anthropological linguists study reference as much as, if not more than, semanticists. Furthermore, Devitt's response is in tension with his claim about the role of corpus studies in the confirmation of theories of reference $(2012,27-8)$ : In contrast to philosophers of language and to most semanticists who rarely, if ever, examine corpora, sociolinguists, historical and anthropological linguists, and discourse analysts often study corpora to understand the variation in, and stability of, reference.

To conclude, it is dubious that philosophical theorizing about reference really enhances the reliability of philosophers' intuitions, and there is thus little reason to accept the Expertise Defense.

\section{Lay People's Intuitions Should be Preferred}

In fact, some reasons even militate for preferring lay people's intuitions about reference to philosophers'. Machery and Stich (2012) examined three reasons that are convincing an increasing number of linguists to examine lay people's linguistic intuitions experimentally instead of consulting the intuitions of a few linguists informally, as they used to. First, linguists' intuitions may sometimes be biased by their own theoretical

\footnotetext{
${ }^{3}$ Alternatively, the intuition-eliciting stimuli could be so complex that linguists' better theories do not give them any advantage.
} 
commitments; second, linguists may speak idiolects that differ from lay people's; third, factorial analyses with large sample sizes are needed to understand how variables interact to determine the grammaticality of syntactic constructions. These three reasons carry over to the intuitions of interest to philosophers of language.

Devitt has nothing to say about the third reason, and he is not impressed by the first one $(2012,21)$. Noting correctly that the influence of linguists' theoretical commitments on their intuitions is an instance of a more general problem - the possible influence of scientists' theories on their judgments - Devitt seems to conclude that this possible influence does not justify preferring lay people's intuitions to philosophers'. This is the wrong conclusion, however. When scientists identify a possible bias, they do not simply mutter "C'est la vie!", but they find ways to control for it, such as randomization, double-blind experiments, and independent coding of data. Similarly, to control for possible biases affecting their own intuitions, linguists have started examining lay people's intuitions experimentally. Philosophers of language should follow suit.

On the other hand, Devitt agrees that the possibility that lay people's and philosophers' idiolects differ justifies examining lay people's intuitions (2012, fn. 28), but this concession is in tension with his plea for the Expertise Defense. Many linguists have concluded from this possibility that the evidential basis of syntactic and semantic theories consists of lay people's linguistic intuitions, and that linguists' intuitions carry less weight than lay people's. By contrast, proponents of the Expertise Defense hold that lay people's intuitions carry less weight than the intuitions of philosophers of language. Devitt should clarify how evidence about experts' intuitions and about lay people's should be combined, particularly when these disagree.

\section{Usage and Metalinguistic Intuitions}

Contrary to what Devitt suggests (2012, 31), I agree that studies of the use of words (in contrast to metalinguistic intuitions) provide relevant evidence to assess theories of reference. However, I disagree with the idea (which Devitt seems to endorse) that they provide better evidence than metalinguistic intuitions.

Linguists do not rely on metalinguistic intuitions because they endorse the Voice of Competence, but because these have two properties: They typically provide evidence about the relevant syntactic and semantic properties that is as reliable, if not more, than occurrences in corpus and production studies, and one is more likely to obtain relevant evidence when one elicits metalinguistic intuitions than when one searches through existing corpora. Consider the first point. Intuitions about synonymy and antonymy provide reliable (but fallible) evidence about synonymy and antonymy; acceptability intuitions provide reliable (but fallible) evidence about the grammaticality of syntactic constructions; etc. Furthermore, metalinguistic intuitions do not suffer from the well-known problems that plague corpus and production studies such as the occurrence of ungrammatical constructions or the reluctance to use some constructions for pragmatic reasons. Turning to the second point, whether corpus studies provide evidence bearing on theoretical controversies is a sheer matter of luck while stud- 
ies of metalinguistic intuitions can be easily engineered so as to provide relevant evidence.

These considerations carry over straightforwardly to the study of intuitions about reference. In particular, the only study that compared intuitions about the reference of proper names and the use of sentences containing proper names found no difference between these two types of evidence (Machery et al. 2009). More precisely, Machery et al. failed to find any difference between people's judgments about the truth of sentences containing proper names and their judgments about the reference of proper names. The former kind of judgments was used as a proxy for the use of these sentences since, except for a few kinds of sentences (e.g., sentences containing indexicals), asserting that a sentence is true means being willing to assert this sentence.

So, yes, philosophers of language should study empirically how lay people use proper names, but, considering the reliability of metalinguistic intuitions and the practical advantages of studying them, they should not shun people's intuitions about reference.

\section{REFERENCES}

Devitt, Michael. 2011. Experimental semantics. Pbilosophy and Phenomenological Research 82: 418-35.

Devitt, Michael. 2012. Whither experimental semantics? Theoria 27/1: 5-36.

Kahneman, Daniel. 2011. Thinking, fast and slow. New York: Farrar, Strauss and Giroux.

Machery, Edouard. 2011. Thought experiments and philosophical knowledge. Metaphilosophy 42: 191-214.

Machery, Edouard. 2012. Expertise and intuitions about reference. Theoria 27/1: 37-54.

Machery, Edouard, and Stephen P. Stich. 2012. Experimental philosophy of language. In Routledge companion to the philosophy of language (pp. 495-512). ed. Gillian Russell and Delia Graff Fara. New York: Routledge.

Machery, Edouard, Christophe Olivola, and Molly de Blanc. 2009. Linguistic and metalinguistic intuitions in the philosophy of language. Analysis 69: 689-94.

Machery, Edouard, Ron Mallon, Shaun Nichols, and Stephen P. Stich. 2004. Semantics, cross-cultural style. Cognition 92: B1-12.

Machery, Edouard, Ron Mallon, Shaun Nichols, and Stephen P. Stich. Forthcoming. If intuitions vary, then so what? Philosophy and Phenomenological Research.

Mallon, Ron, Machery, Edouard, Shaun Nichols, and Stephen P. Stich. 2009. Against arguments from reference. Philosophy and Phenomenological Research 79: 332-56.

Edouard Machery is Associate Professor in the Department of History and Philosophy of Science at the University of Pittsburgh, a Fellow of the Center for Philosophy of Science at the University of Pittsburgh, and a member of the Center for the Neural Basis of Cognition (Pittsburgh-CMU). He is the author of Doing without Concepts (OUP, 2009), the editor of the Oxford Handbook of Compositionality (OUP, 2012), Arguing about Human Nature (Routledge, forthcoming), and of Controversies in Experimental Philosophy (Routledge, forthcoming), and he has been an associate editor of The European Journal for Philosophy of Science since 2009 and the editor of the naturalistic philosophy section of Philosophy Compass since 2012.

Address: Department of History and Philosophy of Science, University of Pittsburgh. $1017 \mathrm{CL}$ Pittsburgh 15260, USA. E-mail: machery@pitt.edu 